Provided for non-commercial research and education use. Not for reproduction, distribution or commercial use.

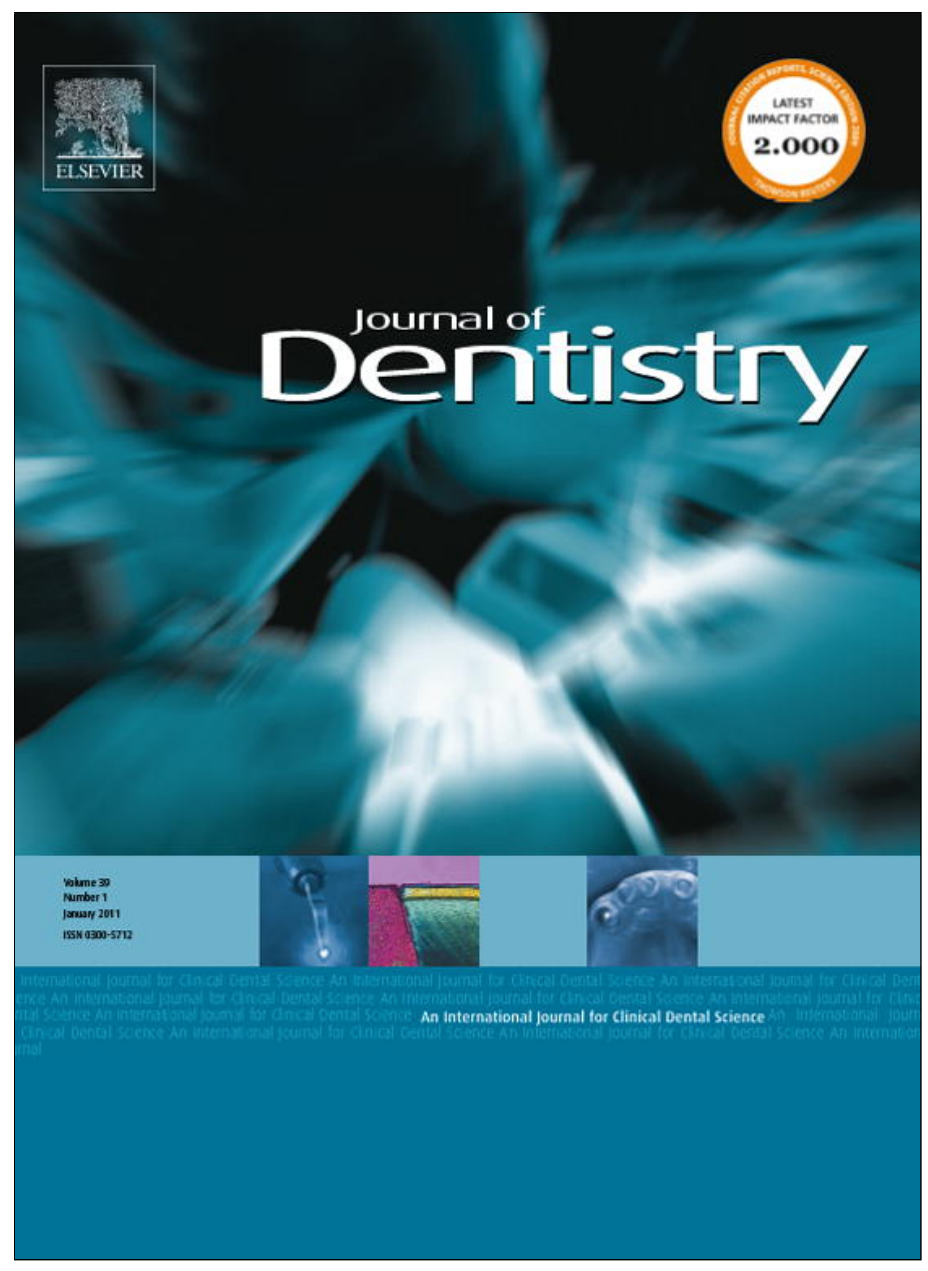

This article appeared in a journal published by Elsevier. The attached copy is furnished to the author for internal non-commercial research and education use, including for instruction at the authors institution and sharing with colleagues.

Other uses, including reproduction and distribution, or selling or licensing copies, or posting to personal, institutional or third party websites are prohibited.

In most cases authors are permitted to post their version of the article (e.g. in Word or Tex form) to their personal website or institutional repository. Authors requiring further information regarding Elsevier's archiving and manuscript policies are encouraged to visit:

http://www.elsevier.com/copyright 


\title{
Clinical study of Mineral Trioxide Aggregate in primary molars. Comparison between Grey and White MTA-A long term follow-up (84 months)
}

\author{
Cristina Cardoso-Silva ${ }^{a, b, *}$, Elena Barbería ${ }^{b}$, Myriam Maroto $^{b}$, Franklin García-Godoy $^{c}$ \\ ${ }^{a}$ Faculty of Dental Medicine, University of Porto, Portugal \\ ${ }^{\mathrm{b}}$ Department of Prevention, Pediatric Dentistry and Orthodontics, Faculty of Odontology, Complutense University of Madrid, Spain \\ c Bioscience Research Center, College of Dentistry, University of Tennessee Health Science Center, Memphis, TN, USA
}

\section{A R T I C L E I N F O}

\section{Article history:}

Received 14 October 2010

Received in revised form

29 November 2010

Accepted 30 November 2010

\section{Keywords:}

Pulpotomy

Primary molars

Mineral Trioxide Aggregate (MTA)

Dentine bridges

Pulp canal stenosis

\begin{abstract}
A B S T R A C T
Objectives: The aim of the present study was to conduct a clinical and radiographic longterm evaluation of pulpotomy in temporary molars performed with Grey and White Mineral Trioxide Aggregate (MTA) and compare the results of Grey and White MTA pulpotomies in a sample of 233 primary molars with a maximum follow-up period of 84 months.

Methods: The sample was selected from patients treated at the Department of Pediatric Dentistry, Faculty of Dentistry, Complutense University of Madrid, Spain. This prospective study included first and second primary molars treated with pulpotomy with Grey or White MTA, controlled for a maximum follow-up period of 84 months. Statistical analysis of clinical and radiographic findings was completed using ANOVA $(P<0.05)$.

Results: Follow-up evaluations, performed every 6 months, revealed that only 2 molars treated with White MTA presented abscess and pathological mobility. Radiographic examination of the 210 molars revealed unfavourable pulp response in only 6 molars (internal or furcation root resorption), without statistically significant differences between Grey and White MTA. Two radiological findings were noticed: dentine bridge formation and partial or total root canal stenosis. Grey MTA induced a higher percentage of dentine bridges with statistically significant differences $(P<0.05)$, and a higher percentage of pulp canal stenosis, without a statistically significant difference.

Conclusions: Grey and White MTA presented high levels of clinical and radiographic success. Although the present study showed evidence of a very good biologic response with both types of MTA, Grey MTA showed significantly higher number of dentine bridge formation than White MTA.
\end{abstract}

(C) 2010 Elsevier Ltd. All rights reserved.
1.

\section{Introduction}

Pulpotomy is still the most frequent endodontic treatment performed on primary molars. ${ }^{1-6}$ This treatment is defined as "a procedure that involves the amputation of the coronal portion of the affected or infected dental pulp". ${ }^{7}$ It is indicated in primary teeth with inflammation of the coronal pulp caused by caries with no involvement of the radicular pulp.

Formocresol remains the most widely used pulpotomy medicament on primary teeth. Its mummifying action is undisputed, but concerns have been expressed given its toxic, carcinogenic and mutagenic potential. ${ }^{8,9}$

\footnotetext{
* Corresponding author at: Rua Dr. Manuel Pereira da Silva, 4200-393 Porto, Portugal. Tel.: +351917613208.

E-mail address: cristinalsilva@mail.telepac.pt (C. Cardoso-Silva). 0300-5712/\$ - see front matter (C) 2010 Elsevier Ltd. All rights reserved. doi:10.1016/j.jdent.2010.11.010
} 
Many alternatives to formocresol have been proposed. One alternative seems to be Mineral Trioxide Aggregate (MTA) as it is a more biologically acceptable product. It was first described in the dental scientific literature by Lee et al. in $1993^{10}$ and patented in 1995 by Torabinejad and White. ${ }^{11}$ In 1998 it was approved by the US Food and Drug Administration as a therapeutic endodontic material for humans. ${ }^{12,13}$

MTA is a mixture of a refined Portland cement, composed by dicalcium silicate, tricalcium silicate, tricalcium aluminate, gypsum and tetracalcium aluminoferrite. It also presents bismuth oxide which makes it radiopaque. ${ }^{14-18}$

In vitro and in vivo investigations have shown that MTA has many properties such as excellent biocompatibility, an alkaline $\mathrm{pH}$, radiopacity, a high sealing capacity and the fact that it hardens in the presence of humidity $2-4 \mathrm{~h}$ after mixing. MTA can also induce the formation of dentine, cement and bone. ${ }^{19-22}$

When MTA was first commercialized it had a grey colouration but in 2002 a new formula was created, the White MTA, to improve on the dark colour properties exhibited by Grey MTA.

In recent years many studies have been published on the use of MTA in permanent teeth. Its use in primary teeth is much more limited and mainly used as a pulp dressing agent in pulpotomy treatments. ${ }^{23}$ Results have shown a very high clinical and radiographic success rate but clinical long-term studies are scarce regarding primary teeth. A previous study evaluated a total of 69 primary molars treated with Grey MTA with a maximum follow-up of 42 months, as well as 13 primary molars treated with White MTA reviewed 6 months after treatment. ${ }^{24}$ Holan et al. investigated MTA effects in 33 pulpotomized molars during a medium follow-up evaluation period of 38.2 months ${ }^{26}$ reporting a success rate of $97 \%$; Naik and Hegde evaluated 25 pulpotomized molars for a period of 6 months showing a success rate of $100 \%{ }^{27}$; Farsi et al. compared the effect of MTA in 60 pulpotomized molars to those of formocresol, followed during 2 years ${ }^{28}$ noting a success rate of $100 \%$.

The aim of the present study was to conduct a clinical and radiographic long-term evaluation of pulpotomy in temporary molars performed with Grey and White MTA and compare the results of Grey and White MTA pulpotomies in a sample of 233 primary molars with a maximum follow-up period of 84 months.

\section{Materials and methods}

The sample of this study was selected from the patients attending the clinic of the Department of Pediatric Dentistry, Faculty of Dentistry, Complutense University of Madrid, Spain, between 2001 and 2009.

This prospective study was designed to include first and second primary molars that had been treated by pulpotomy with Grey or White ProRoot ${ }^{\circledR}$ MTA (Tulsa Dental Products, Tulsa, OK, USA). The authors had been previously involved in several pulpotomy studies and used a standardized technique. The inclusion criteria in the study were:
1. Subjects with no systemic pathology or allergies;

2. Primary molars which needed a pulpotomy treatment due to caries;

3. Primary molars revealing no clinical or radiographic signs of radicular pulp degeneration (i.e. abscesses, associated fistulous tracts, increased mobility, furcation involvement, internal or external pathological root resorption, or pathological thickening of the periodontal membrane);

4. Primary molars which could be restored with stainless steel crown;

5. Primary molars which had not been previously treated;

6. Primary molars presenting, at treatment time, at least half of the root length;

7. Primary molars in which the operator strictly followed the same protocol, described by Maroto et al., ${ }^{25}$ performing the pulpotomy:

(a) Complete isolation with rubber dam.

(b) Preparation of the molar and fitting of a stainless steel crown.

(c) Removal of the carious tissue with a round bur.

(d) Elimination of the roof of the pulp chamber and removal of the coronal pulp tissue with a large low speed round bur.

(e) Drying and control of the pulp haemorrhage using slight pressure with a sterile cotton wool pellet.

(f) Mixing of the MTA with sterile water on a glass slab following the manufacturer's instructions.

(g) Pressing the MTA to the walls and floor of the pulp chamber with a cotton wool pellet moistened in sterile water.

(h) Filling the pulp chamber with light-curing glassionomer cement.

(i) Cementation of the stainless steel crown with selfcuring glass-ionomer cement.

The sample consisted of 233 primary molars (98 maxillary molars and 135 mandibular molars). Twenty-three molars were not included in the study as they belonged to patients who did not show up to follow-up visits. Therefore, our final sample included 210 primary molars:

- Molars treated with Grey MTA: 33 maxillary molars (18 first molars; 15 second molars) and 41 mandibular molars (20 first molars; 21 second molars).

- Molars treated with White MTA: 57 maxillary molars (28 first molars; 29 second molars) and 79 mandibular molars (38 first molars; 41 second molars).

Follow-up time ranged between 6 and 84 months.

Prior to the beginning of the study, approval from the ethics committee of the Clinical Hospital of San Carlos, Madrid, Spain (\#P-05/346) and parental informed consent was obtained. Also, calibration between the examiner and the evaluator was performed.

The same data were collected by the examiner and the evaluator separately, following the same criteria, in order to evaluate the agreement between the result readings and involved clinical and radiographic examination of each treated molar and its radicular area. The UCM Research Support Service (RSS) evaluated concordance between exam- 


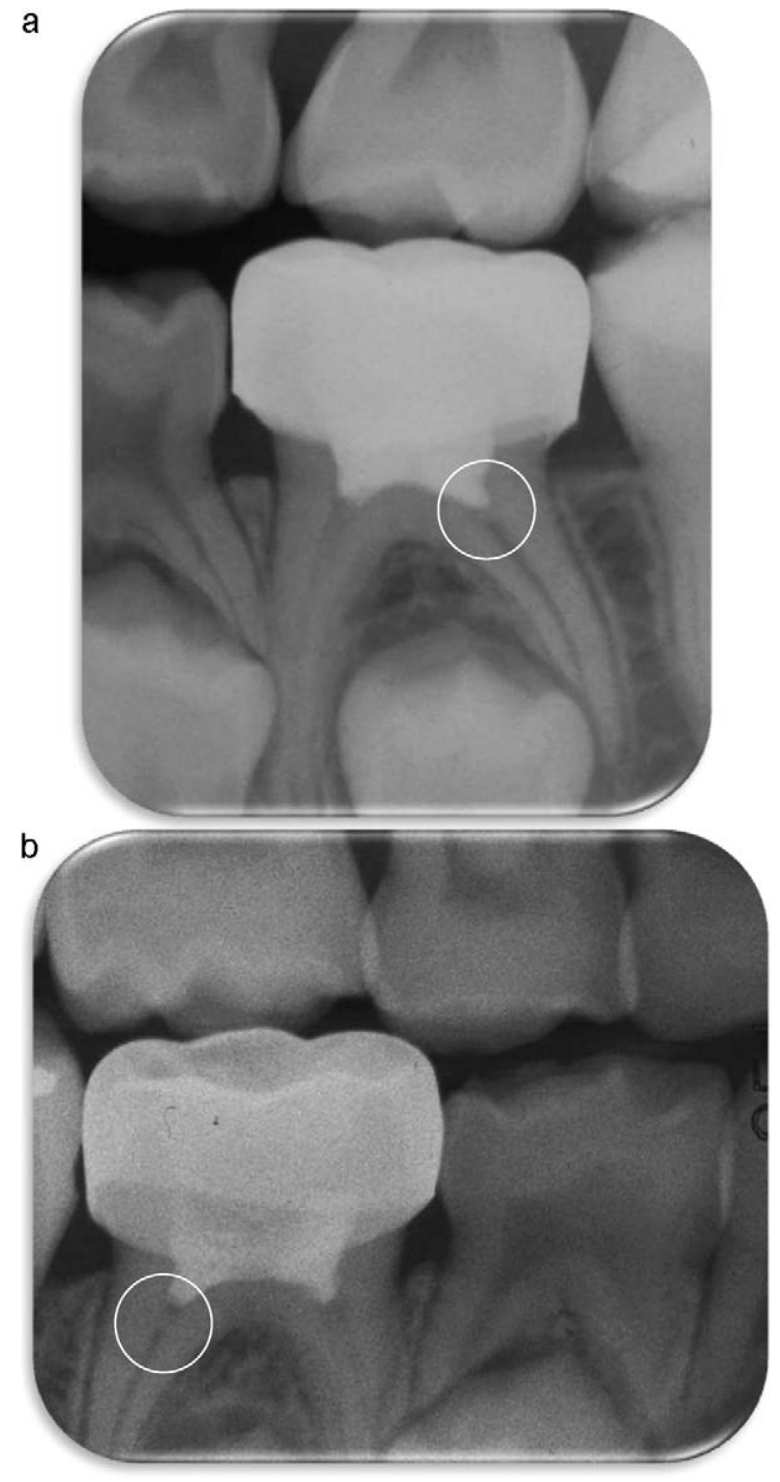

Fig. 1 - (a) Radiograph obtained 8 months after treatment with Grey MTA indicating the dentine bridge and (b) radiograph obtained 16 months after treatment with White MTA indicating the dentine bridge.

iners through the use of Kappa index $(\kappa=0.93 ; P<0.05)$. The treatment was considered a failure if one or more of these signs were observed: inflammation, abscess or fistula in the soft tissues, pathological mobility, spontaneous pain or due to percussion, pathological thickening of the periodontal membrane, or dissolution of the MTA.

During radiographic examination, reparative dentine deposition, the number of dentine bridges, and the presence of pulp canal stenosis were recorded. To correctly calculate this deposition, only the mandibular molars were taken into account because radiographic superimposition due to the presence of three roots in maxillary molars would result in false positives.

Statistical analyses of the results of clinical and radiographic evaluation were completed using SPSS 17.0 Software (SPSS Inc., Chicago, IL, USA). The Kappa index was performed to determine variations within and between examiners. A descriptive analysis was performed to obtain frequencies and percentages of clinical and radiographic response, as well an ANOVA of repeated measures with Greenhouse-Geisser correction. Statistical significance was established for $P<0.05$.

\section{Results}

Kappa index revealed agreement between data collected from the examiner and the observer $(\kappa=0.93)$; therefore, the data collected by the examiner were used for the statistical analysis.

\subsection{Clinical evaluation}

Six months after treatment signs of clinical success were found in all treated molars. Successive follow-up evaluations, performed every 6 months, revealed 2 molars treated with White MTA presented abscess and pathological mobility: a first right upper primary molar (54) after 12 months and a second right upper primary molar (55) after 36 months. Both molars were extracted.

\subsection{Radiographic evaluation}

MTA remained in the pulp chamber of all molars without showing any signs of resorption or displacement over time.

Radiographic examination of the 210 molars revealed radiographical signs of unfavourable pulp response in only 6 molars, mainly consisting of internal or furcation root resorption. These molars were monitored until their physiological exfoliation.

There were no statistically significant differences on the radiographic signs of unfavourable pulp response between molars treated with Grey and White MTA $(P=0.141)$.

\subsection{Reparative dentine formation evidence}

The periodic radiographic follow-up examinations revealed two kinds of findings considered as signs of a favourable pulp response: dentine bridges in the area immediately below the MTA (Fig. 1), and partial or total radicular pulp canal stenosis (Fig. 2).

The total number of root canals studied for this purpose was 240: 82 treated with Grey MTA and 158 treated with White MTA, monitored every 6 months for a maximum period of 84 months (Table 1).

Dentine bridges were already present in $31.7 \%$ of the canals after 6 months of treatment with Grey MTA. This percentage increased as the evaluation time increased reaching $100 \%$ of the sample reviewed at the end of the study ( 84 months). In order to compare the existence of differences and similarities between left and right molars as well as between first and second temporary molars a statistical adjustment was made and molars with a follow-up time of at least 30 months were selected. Through this analysis it was possible to evaluate differences between percentages and behavioural profile throughout time, which were not statistically significant in the group of molars treated with Grey MTA. Nevertheless, it 


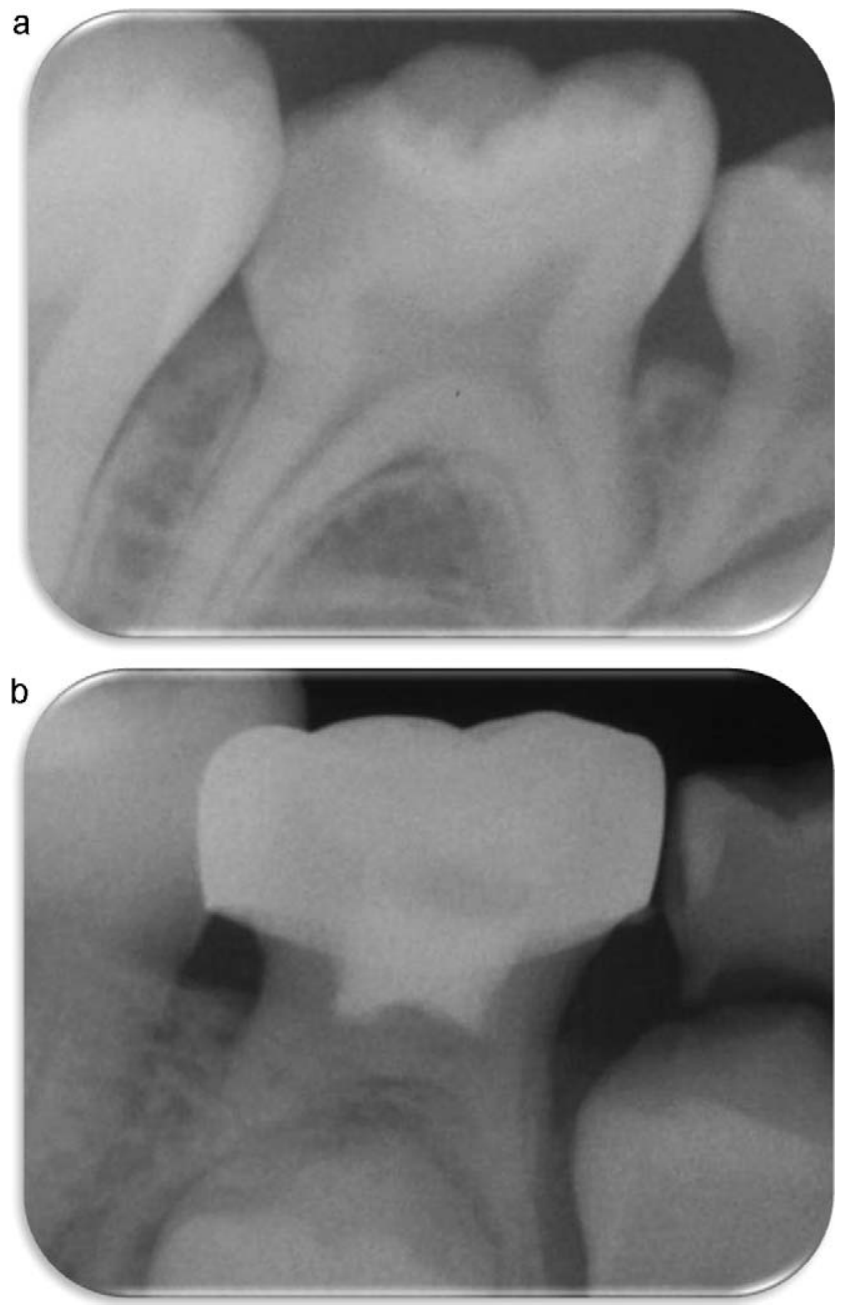

Fig. 2 - (a) Radiograph obtained before pulpotomy treatment and (b) radiograph obtained 42 months after treatment with Grey MTA where root canal stenosis can be observed.

was observed that the presence of dentine bridges increased with time; as the contact time between MTA and the radicular pulp increased, dentine deposition was more frequently observed.

Dentine bridges were present in $18.5 \%$ of the root canals after 6 months of treatment with White MTA, in 50\% after 30 months and in $83.3 \%$ after 54 months. The comparative analysis revealed that in this case there were no statistically significant differences between percentages and behavioural profile throughout time as for Grey MTA, but, once again, time significantly influenced the appearance of dentine bridges. The distribution of observed dentine bridges in molars treated with Grey and White MTA is presented in Table 2.

Stenosis of the radicular pulp canals was present in $14.6 \%$ of the canals treated with Grey MTA 6 months after treatment, $57.1 \%$ after 12 months and $86.4 \%$ after 24 months. At the end of the study, 84 months, every canal treated with Grey MTA presented stenosis. The comparative analysis revealed that there were statistically significant differences between beha-
Table 1 - Distribution of root canals radiologically

studied in each follow-up review to analyse dentine bridges and pulp canal stenosis formation.

\begin{tabular}{lcc} 
Time & Total number of mandibular root canals \\
\cline { 2 - 3 } & Grey MTA & White MTA \\
\hline 6 months & 82 & 158 \\
12 months & 70 & 144 \\
18 months & 70 & 114 \\
24 months & 66 & 90 \\
30 months & 60 & 74 \\
36 months & 50 & 58 \\
42 months & 38 & 32 \\
48 months & 32 & 20 \\
54 months & 30 & 6 \\
60 months & 24 & 2 \\
66 months & 20 & 0 \\
72 months & 16 & 0 \\
78 months & 16 & 0 \\
84 months & 10 & 0 \\
\hline
\end{tabular}

vioural profile throughout time for left lower molars and right lower molars but no differences between percentages of radicular pulp canal stenosis.

Molars which have been treated with White MTA presented stenosis in $24.7 \%$ of the root canals 6 months after treatment, in $54.2 \%$ after 12 months, $79.7 \%$ after 30 months and it was after 54 months that all the canals presented stenosis. The comparative analysis revealed significant differences between the percentages of stenosis observed on left and right first molars, but no differences in the behavioural profile. The distribution of observed root canal stenosis in molars treated with Grey and White MTA is presented in Table 3.

Comparing the dentine bridge percentages observed in root canals treated with Grey MTA with those treated with White MTA, the authors observed that, in general, higher percentages were obtained when Grey MTA was used. These differences were statistically significant $(P<0.05)$.

A higher percentage of stenosis in the root canals treated with Grey MTA was noticed, but without statistical significance. There were no differences in the behavioural profile between the two types of MTA.

\section{Discussion}

Since MTA has been used in pulpotomies of temporary molars, clinical and radiological evidence-based success rates have been demonstrated. In many scientific articles the authors expressed the need for studies with larger samples and longer follow-up periods; the present study far exceeds previously published ones: 210 molars periodically evaluated for a maximum of 84 months. Moreover, this study evaluated and compared the two types of MTA: Grey and White.

The clinical success rate of molars treated with Grey MTA in this study was $100 \%$. This percentage coincides with the results obtained in other investigations. ${ }^{23,27-32}$ Molars treated with White MTA exhibited a clinical success rate of $93 \%$ as two cases presented abscess and non physiological mobility. Maroto et al. ${ }^{24}$ obtained a higher clinical success rate, $100 \%$, in a 6-month follow-up as did Noorollahian in a 24-month 
Table 2 - Percentage of root canals presenting dentine bridges in each follow-up, distributed by molar and type of MTA.

Follow-up time

Molar

\begin{tabular}{|c|c|c|c|c|c|c|c|c|}
\hline & \multicolumn{2}{|c|}{$\begin{array}{c}74 \\
\% \text { RC }\end{array}$} & \multicolumn{2}{|c|}{$\begin{array}{c}75 \\
\% \text { RC }\end{array}$} & \multicolumn{2}{|c|}{$\begin{array}{c}84 \\
\% \text { RC }\end{array}$} & \multicolumn{2}{|c|}{$\begin{array}{c}85 \\
\% \text { RC }\end{array}$} \\
\hline & GMTA & WMTA & GMTA & WMTA & GMTA & WMTA & GMTA & WMTA \\
\hline 6 months & 20.8 & 19.4 & 26.9 & 19.6 & 62.5 & 22.5 & 50 & 11.1 \\
\hline 12 months & 37.5 & 47.1 & 66.7 & 42.9 & 62.5 & 50 & 41.7 & 34.4 \\
\hline 18 months & 45.8 & 46.9 & 72.2 & 47.1 & 62.5 & 59.1 & 41.7 & 38.5 \\
\hline 24 months & 50 & 50 & 72.2 & 38.5 & 75 & 50 & 58.3 & 38.9 \\
\hline 30 months & 55.6 & 54.2 & 81.3 & 40.9 & 85.7 & 66.7 & 58.3 & 43.8 \\
\hline 36 months & 62.5 & 65 & 91.7 & 50 & 85.7 & 60 & 60 & 58.3 \\
\hline 42 months & 66.7 & 75 & 90 & 40 & 80 & 25 & 83.3 & 66.7 \\
\hline 48 months & 80 & 70 & 90 & 37.5 & 100 & - & 100 & 100 \\
\hline 54 months & 87.5 & 75 & 90 & 100 & 100 & - & 100 & - \\
\hline 60 months & 83.3 & 100 & 100 & - & 100 & - & 100 & - \\
\hline 66 months & 83.3 & - & 100 & - & 100 & - & 100 & - \\
\hline 72 months & 75 & - & 100 & - & 100 & - & 100 & - \\
\hline 78 months & 75 & - & 100 & - & 100 & - & 100 & - \\
\hline 84 months & 100 & - & 100 & - & - & - & 100 & - \\
\hline
\end{tabular}

$\%$ RC: percentage of root canals presenting dentine bridges.

GMTA: Grey Mineral Trioxide Aggregate.

WMTA: White Mineral Trioxide Aggregate.

follow-up. In contrast, Agamy et al. ${ }^{31}$ obtained a lower clinical success rate, $80 \%, 12$ months after treatment.

Other studies have reported that teeth treated with Grey MTA presented colour changes after treatment. ${ }^{27,33} \mathrm{Al}-$ though we could not find in the scientific literature any report of discolouration in teeth treated with White MTA, in our daily practice we have also observed this phenomenon in primary incisors, canines and molars. In the present investigation, any discolouration that might have occurred did not represent an aesthetic problem as all molars were restored with a stainless steel crown, as recommended by other authors. ${ }^{24}$ In this study it was decided to use stainless steel crowns for two different reasons. First, the success of pulpotomy treatments not only depends on the effect of the material used, but is directly related to the ability of both materials, filling and final restoration, to achieve a good biological seal against immediate and long term microleakage. Also, the majority of human clinical investigations with which we compared our study results, used preformed stainless crowns. ${ }^{5,23,24,27,28,32,34}$

In the radiographic analysis performed every 6 months no signs of displacement or resorption of the MTA was seen. None

Table 3 - Percentage of root canals presenting stenosis in each follow-up, distributed by molar and type of MTA.

Follow-up time

Molar

\begin{tabular}{|c|c|c|c|c|c|c|c|c|}
\hline & \\
\hline & \multirow{2}{*}{\multicolumn{2}{|c|}{$\begin{array}{c}74 \\
\% \text { RC }\end{array}$}} & \multirow{2}{*}{\multicolumn{2}{|c|}{$\begin{array}{c}75 \\
\% \text { RC }\end{array}$}} & \multirow{2}{*}{\multicolumn{2}{|c|}{$\begin{array}{c}84 \\
\% \text { RC }\end{array}$}} & \multirow{2}{*}{\multicolumn{2}{|c|}{$\begin{array}{c}85 \\
\% R C\end{array}$}} \\
\hline & & & & & & & & \\
\hline & GMTA & WMTA & GMTA & WMTA & GMTA & WMTA & GMTA & WMTA \\
\hline 6 months & 16.7 & 19.4 & 19.2 & 26.1 & - & 22.5 & 18.8 & 30.6 \\
\hline 12 months & 41.7 & 41.2 & 72.2 & 61.9 & 62.5 & 41.7 & 58.3 & 71.9 \\
\hline 18 months & 58.3 & 62.5 & 72.2 & 64.7 & 87.5 & 54.5 & 83.3 & 73 \\
\hline 24 months & 70 & 82.1 & 83.3 & 73.1 & 100 & 50 & 100 & 94.4 \\
\hline 30 months & 77.8 & 87.5 & 81.3 & 77.3 & 100 & 50 & 100 & 93.8 \\
\hline 36 months & 75 & 95 & 91.7 & 93.8 & 100 & 70 & 100 & 100 \\
\hline 42 months & 75 & 91.7 & 90 & 90 & 100 & 100 & 100 & 100 \\
\hline 48 months & 70 & 90 & 90 & 100 & 100 & - & 100 & 100 \\
\hline 54 months & 62.5 & 100 & 90 & 100 & 100 & - & 100 & - \\
\hline 60 months & 66.7 & 100 & 100 & - & 100 & - & 100 & - \\
\hline 66 months & 66.7 & - & 100 & - & 100 & - & 100 & - \\
\hline 72 months & 50 & - & 100 & - & 100 & - & 100 & - \\
\hline 78 months & 50 & - & 100 & - & 100 & - & 100 & - \\
\hline 84 months & 100 & - & 100 & - & - & - & 100 & - \\
\hline
\end{tabular}

$\%$ RC: percentage of root canals presenting stenosis.

GMTA: Grey Mineral Trioxide Aggregate.

WMTA: White Mineral Trioxide Aggregate. 
of the molars treated with Grey MTA showed pathological signs, resulting in a $100 \%$ radiographic success. This success rate is consistent with that found by most investigations, even with different follow-up times. ${ }^{23,27,31,34}$ On the contrary, Holan et al. obtained a radiographic success rate of $97 \%$ in molars with a media follow-up time of 38.2 months. $^{26}$

In molars treated with White MTA, radiographic success was achieved in $93 \%$ of the molars. The remaining $7 \%$ presented internal root resorption and were kept under observation as they were asymptomatic and did not show any signs of clinical failure, until their physiological exfoliation. This result was similar to that obtained by Noorollahian (94\%) in a 24-month follow-up ${ }^{32}$ and higher than the success rate obtained by Agamy et al. (80\%) in a 12month follow-up. ${ }^{31}$

Based on the results obtained in the present investigation for both types of MTA we can verify that the success rates differ depending on the type of MTA: Grey MTA allowed higher clinical and radiographic success rates. The two types of MTA differ in composition due to the raw materials used on their manufacture: the White material differ from the Grey by an absence of iron. ${ }^{35}$ Also White MTA particles are finer than Grey MTA, which would explain the different handling of the material as explained by Camilleri et al. ${ }^{35}$ Agamy et al. $^{31}$ also suggested that the difference in composition between these two types of MTA, in particular the presence of tetracalcium aluminoferrite in Grey MTA, may be the cause for different results. These authors also preformed a histological evaluation of molars treated with either Grey or White MTA and found that, when White MTA was used, molars presented more areas of necrosis and inflammatory cells. ${ }^{31}$

In the present study, radiographic analysis revealed deposition of reparative dentine in the pulp canals in most of the cases. This was shown by dentine bridge formation and the presence of pulp canal stenosis in radiographic images. Dentine formation showed the presence of odontoblastic activity which demonstrated the root canal pulp vitality and the absence of pathology of the treated molars. ${ }^{24,32}$

Comparing dentine bridge formation between the two types of MTA, globally, Grey MTA induced the formation of a higher number of dentine bridges. This difference was statistically significant $(P<0.05)$. Although pulp canals treated with Grey MTA exhibited a higher percentage of pulp canal stenosis than White MTA, this difference was not statistically significant. On these results, our investigation agrees with others previously published. ${ }^{24,32}$

\section{Conclusions}

According to the results of this study, we may conclude that Mineral Trioxide Aggregate, Grey and White, presents a high level of clinical and radiographic success, which allows it to be indicated as a substitute to formocresol in pulpotomies of primary molars without presenting any adverse results.

Although this study has shown evidence of a very good biologic response with both types of MTA, Grey and White, Grey MTA showed better results as it induced dentine formation more efficiently than White MTA.

\section{R E F E R E N C E S}

1. Nunn JH, Smeaton I, Gilory J. The development of formocresol as a medicament for primary molar pulpotomy procedures. Journal of Dentistry for Children 1996;63:51-3.

2. Roberts JF. Treatment of vital and non-vital primary molar teeth by one-stage formocresol pulpotomy: clinical success and effect upon age of exfoliation. International Journal of Paediatric Dentistry 1996;6:111-5.

3. Waterhouse PJ, Nunn JH, Whitworth JM, Soames JV. Primary molar pulp therapy-histological evaluation of failure. International Journal of Paediatric Dentistry 2000;10:313-21.

4. Vij R, Coll JA, Shelton P, Farooq NS. Caries control and other variables associated with success of primary molar vital pulp therapy. Pediatric Dentistry 2004;26:214-20.

5. Fuks AB, Holan G, Davis JM, Eidelman E. Ferric sulfate versus dilute formocresol in pulpotomized primary molars: longterm follow up. Pediatric Dentistry 1997;19:327-30.

6. Ranly DM, Garcia-Godoy F. Current and potential pulp therapies for primary and young permanent teeth. Journal of Dentistry 2000;28:153-61.

7. American Academy of Pediatric Dentistry. Guideline on pulp therapy for primary and young permanent teeth. Pediatric Dentistry 2005-2006;27(7 Suppl.):130-4.

8. Ketley CE, Goodman JR. Formocresol toxicity: is there a suitable alternative for pulpotomy of primary molars? International Journal of Paediatric Dentistry 1991;1:67-72.

9. Milnes A. Is formocresol obsolete? A fresh look at the evidence concerning safety issues. Pediatric Dentistry 2008;30:237-43.

10. Lee S, Monsef M, Torabinejad M. Sealing ability of a Mineral Trioxide Aggregate for repair of lateral root perforations. Journal of Endodontics 1993;19:541-4.

11. Torabinejad $\mathrm{M}$, White DJ. Tooth filling material and use. US Patent number 5,769,638.

12. Dentsply Endodontics. Materials safety data sheet (MSDS): ProRoot MTA (mineral trioxide aggregate) root canal repair material. Effective March 1, 2001.

13. Torabinejad M, Hong CU, McDonald F, Pitt Ford TR. Physical and chemical properties of a new root-end filling material. Journal of Endodontics 1995;21:349-53.

14. Roberts HW, Toth J, Berzins D, Charlton D. Mineral trioxide aggregate material use in endodontic treatment: a review of the literature. Dental Materials 2008;24:149-64.

15. Camilleri J, Montesin F, Brady K, Sweeney R, Curtis R, Pitt Ford $\mathrm{T}$. The constitution of mineral trioxide aggregate. Dental Materials 2005;21:297-303.

16. Camilleri J. Hydration mechanisms of mineral trioxide aggregate. International Endodontic Journal 2007;40: $462-70$.

17. Camilleri J, Pitt Ford T. Mineral trioxide aggregate: a review of the constituents and biological properties of the material. International Endodontic Journal 2006;39:747-54.

18. Coutinho-Filho T, Deus G, Klein L, Manera G, Peixoto C, Gurgel-Filho E. Radiopacity and histological assessment of Portland cement plus bismuth oxide. Oral Surgery Oral Medicine Oral Pathology Oral Radiology and Endodontics 2008;106:e69-77.

19. Mitchell P, Pitt Ford T, Torabinejad M, McDonald F. Osteoblast biocompatibility of mineral trioxide aggregate. Biomaterials 1999;20:167-73.

20. Abdullah D, Pitt Ford TR, Papaioannou S, Nicholson J, McDonald F. An evaluation of accelerated Portland cement as a restorative material. Biomaterials 2002;23:4001-10.

21. Vasconcelos B, Bernardes R, Cruz S, Duarte M, Padilha P, Bernardineli $\mathrm{N}$, et al. Evaluation of $\mathrm{pH}$ and calcium ion release of new root-end filling materials. Oral Surgery Oral 
Medicine Oral Pathology Oral Radiology and Endodontics 2009;108:135-9.

22. Agrabawi J. Sealing ability of amalgam, super EBA cement, and MTA when used as retrograde filling materials. British Dental Journal 2000;188:266-8.

23. Maroto M, Barbería E, Planells P. Dentin bridge formation after mineral trioxide aggregate (MTA) pulpotomías in primary teeth. American Journal of Dentistry 2005;18: $151-4$.

24. Maroto M, Barbería E, Vera V, García-Godoy F. Dentin bridge formation after white mineral trioxide aggregate (white MTA) pulpotomies in primary molars. American Journal of Dentistry 2006;19:75-9.

25. Maroto M, Barbería E, Vera V, Garcia-Godoy F. Mineral Trioxide Aggregate as pulp dressing agent in pulpotomy treatment of primary molars: $42-$ month clinical study. American Journal of Dentistry 2007;20:283-6.

26. Holan G, Eidelman E, Fuks A. Long-term evaluation of pulpotomy in primary molars using mineral trioxide aggregate or formocresol. Pediatric Dentistry 2005;27:129-36.

27. Naik S, Hegde A. Mineral trioxide aggregate as a pulpotomy agent in primary molars: an in vivo study. Journal of the Indian Society of Pedodontics and Preventive Dentistry 2005;23:13-6.

28. Farsi N, Alamoudi N, Balto K, Mushayt. Success of mineral trioxide aggregate in pulpotomized primary molars. Journal of Clinical Pediatric Dentistry 2005;29:307-12.
29. Caceido R, Abbott PV, Alongi DJ, Alarcon MY. Clinical, radiographic and histological analysis of the effects of mineral trioxide aggregate used in direct pulp capping and pulpotomías of primary teeth. Australian Dental Journal 2006;51:297-305.

30. Aeinehchi M, Dadvand S, Fayazi S, Bayat-Movahed S. Randomized controlled trial of mineral trioxide aggregate and formocresol for pulpotomy in primary molar teeth. International Endodontic Journal 2007;40:261-7.

31. Agamy H, Bakry N, Mounir M, Avery D. Comparison of mineral trioxide aggregate and formocresol as pulp-capping agents in pulpotomized primary teeth. Pediatric Dentistry 2004;26:302-9.

32. Noorollahian H. Comparison of mineral trioxide aggregate and formocresol as pulp medicaments for pulpotomías in primary molars. British Dental Journal 2008;204:E20.

33. Jacobovitz M, de Pontes Lima RK. The use of calcium hydroxide and mineral trioxide aggregate on apexification of a replanted tooth: a case report. Dental Traumatology 2009;25:e32-6.

34. Eidelman E, Holan G, Fuks A. Mineral trioxide aggregate vs. formocresol in pulpotomized primary molars: a preliminary report. Pediatric Dentistry 2001;23:15-8.

35. Camilleri J, Montesin FE, Di Silvio L, Pitt Ford TR. The constitution and biocompatibility of accelerated Portland cement for endodontic use. International Endodontic Journal 2005;38:834-42. 